\title{
Late remote ischemic preconditioning in children undergoing cardiopulmonary bypass: A randomized controlled trial
}

\author{
Marcos A. Pavione, MD, ${ }^{\mathrm{a}}$ Fabio Carmona, MD, ${ }^{\mathrm{a}}$ Margaret de Castro, MD, ${ }^{\mathrm{b}}$ and Ana P. C. P. Carlotti, $\mathrm{MD}^{\mathrm{a}}$
}

\begin{abstract}
Objective: Cardiopulmonary bypass is associated with ischemia-reperfusion injury to multiple organs. We aimed to evaluate whether remote ischemic preconditioning performed the day before surgery for congenital heart disease with cardiopulmonary bypass attenuates the postoperative inflammatory response and myocardial dysfunction.
\end{abstract}

\begin{abstract}
Methods: This was a prospective, randomized, single-blind, controlled trial. Children allocated to remote ischemic preconditioning underwent 4 periods of 5 minutes of lower limb ischemia by a blood pressure cuff intercalated with 5 minutes of reperfusion. Blood samples were collected 4, 12, 24, and 48 hours after cardiopulmonary bypass to evaluate nuclear factor kappa $\mathrm{B}$ activation in leukocytes by quantification of mRNA of I kappa $\mathrm{B}$ alpha by real-time quantitative polymerase chain reaction and for interleukin- 8 and 10 plasma concentration measurements by enzyme-linked immunosorbent assay. Myocardial dysfunction was assessed by N-terminal pro-B-type natriuretic peptide and cardiac troponin I plasma concentrations, measured by chemiluminescence, and clinical parameters of low cardiac output syndrome.

Results: Twelve children were allocated to remote ischemic preconditioning, and 10 children were allocated to the control group. Demographic data and Risk Adjustment for Congenital Heart Surgery 1 classification were comparable in both groups. Remote ischemic preconditioning group had lower postoperative values of $\mathrm{N}$-terminal pro-B-type natriuretic peptide, but cardiac troponin I levels were not significantly different between groups. Interleukin-8 and 10 concentrations and I kappa B alpha gene expression were similar in both groups. Postoperative morbidity was similar in both groups; there were no postoperative deaths in either group.
\end{abstract}

Conclusions: Late remote ischemic preconditioning did not provide clinically relevant cardioprotection to children undergoing cardiopulmonary bypass. (J Thorac Cardiovasc Surg 2012;144:178-83)

Supplemental material is available online.

Cardiopulmonary bypass $(\mathrm{CPB})$ is associated with ischemia-reperfusion injury to multiple organs. Ischemia-reperfusion injury leads to the formation of oxygen free radicals, infiltration of neutrophils and release of cytokines, activation of the coagulation cascade and the kallikrein system, and increased cell and mitochondria permeability. ${ }^{1}$

\footnotetext{
From the Division of Pediatric Critical Care Medicine, ${ }^{\mathrm{a}}$ Department of Pediatrics, and Division of Endocrinology, ${ }^{\mathrm{b}}$ Department of Internal Medicine, Hospital das Clínicas, Faculty of Medicine of Ribeirão Preto, University of São Paulo, Ribeirão Preto, Brazil.

This study was supported by Fundação de Amparo à Pesquisa do Estado de São Paulo, Grant 2008/05067-8.

Disclosures: Authors have nothing to disclose with regard to commercial support.

Received for publication July 27, 2011; revisions received Oct 4, 2011; accepted for publication Dec 14, 2011; available ahead of print Jan 13, 2012.

Address for reprints: Ana P. C. P. Carlotti, MD, Department of Pediatrics, Hospital das Clínicas, Faculty of Medicine of Ribeirão Preto, University of São Paulo, Avenida dos Bandeirantes, 3900, 14049-900, Ribeirão Preto SP, Brazil (E-mail: apcarlotti@ fmrp.usp.br).

0022-5223/\$36.00

Copyright (c) 2012 by The American Association for Thoracic Surgery

doi:10.1016/j.jtcvs.2011.12.029
}

Ischemic preconditioning is a phenomenon of organ protection promoted by brief periods of nonlethal ischemia that protect against subsequent lethal ischemia. Remote ischemic preconditioning (RIPC) is a technique in which transient ischemia in one tissue or organ confers subsequent protection to distant organs subjected to potentially lethal ischemia. The first phase of protection, called "early ischemic preconditioning," manifests immediately after the stimulus and lasts for 1 to 2 hours. The second phase, called the "second window of protection" or "late ischemic preconditioning," appears 24 to 48 hours later and lasts for 48 to 72 hours. $^{2}$

The mechanism of protection induced by RIPC involves the release of one or more substances into the systemic circulation that have multiorgan protective effects. ${ }^{3,4}$ Cardioprotection induced by late ischemic preconditioning involves upregulation of anti-inflammatory gene expression, suppression of proinflammatory genes, and reduction of neutrophil adhesion. ${ }^{3,5}$ To date, there are no published studies on the effects of late ischemic preconditioning performed alone in pediatric patients undergoing cardiac surgery with CPB. Thus, we aimed to investigate whether RIPC performed 24 hours before cardiac surgery with CPB would reduce the inflammatory response and myocardial dysfunction in children with congenital heart disease. 


$$
\begin{aligned}
& \text { Abbreviations and Acronyms } \\
& \begin{aligned}
\mathrm{CPB} & =\text { cardiopulmonary bypass } \\
\mathrm{cTnI} & =\text { cardiac troponin I } \\
\mathrm{I} \kappa \mathrm{B} \alpha & =\mathrm{I} \text { kappa } \mathrm{B} \text { alpha } \\
\mathrm{IL} & =\text { interleukin } \\
\mathrm{NF}-\kappa \mathrm{B} & =\text { nuclear factor } \text { kappa } \mathrm{B} \\
\mathrm{NT}- & =\text { N-terminal pro-B-type natriuretic } \\
\text { proBNP } & \text { peptide } \\
\text { PELOD } & =\text { Pediatric Logistic Organ Dysfunction } \\
\text { PICU } & =\text { pediatric intensive care unit } \\
\text { RACHS } & =\text { Risk Adjustment for Congenital Heart } \\
& \text { Surgery } \\
\text { RIPC } & =\text { remote ischemic preconditioning } \\
\text { TnI } & =\text { troponin I }
\end{aligned}
\end{aligned}
$$

\section{PATIENTS AND METHODS}

This is a prospective, randomized, single-blind, controlled trial. The study was approved by the Institutional and National Research Ethics Boards and registered at the international registry of clinical trials in humans (www.clinicaltrial.gov) under the number NCT00868101. Written informed consent was obtained from the patients' parents. Children aged 1 month to 2 years admitted to the Pediatric Cardiology ward in the preoperative period and to the pediatric intensive care unit (PICU) in the postoperative period were eligible for the study. The noninclusion criteria were the presence of genetic syndromes, uncontrolled infection preoperatively, immunodeficiency, class I of Risk Adjustment for Congenital Heart Surgery (RACHS) 1 score, ${ }^{6}$ and nonapproval by parents. The exclusion criteria were incomplete application of the preconditioning protocol and parents' request.

After informed consent was obtained, patients were randomized to the experimental or control group by means of a list generated by a computerized system that uses a random number generator to produce customized sets of random numbers (www.randomizer.org). Patients allocated to the RIPC group underwent 4 periods of 5 minutes of lower limb ischemia intercalated with 5 minutes of reperfusion on the cardiology ward approximately 24 hours before cardiac surgery. By using an electronic sphygmomanometer (Dixtal model 2710; Dixtal Biomedica, São Paulo, Brazil) with an appropriately sized cuff, the patients had their blood pressure measured twice in the legs with a 2-minute interval between measurements. A $12 \times 6-\mathrm{cm}$ sphygmomanometer cuff (Becton Dickinson, Franklin Lakes, NJ) was then inflated in the same leg to a pressure $15 \mathrm{~mm} \mathrm{Hg}$ above the average of the previously measured values of the systolic pressure, and the limb was maintained ischemic with the cuff inflated for 4 periods of 5 minutes, which were intercalated with periods of 5 minutes of reperfusion. All parents were invited to stay with their child during preconditioning. Minimal sedation with oral chloral hydrate $(40 \mathrm{mg} / \mathrm{kg})$ or intravenous midazolam $(0.1-0.2 \mathrm{mg} / \mathrm{kg})$ was used in cases of extreme patient anxiety related to the procedure.

All patients were operated on by the same cardiac surgery team. CPB was performed using a BM-6 device (Edwards Lifesciences, Irvine, Calif) with alpha-stat at $28^{\circ} \mathrm{C}$, colloid priming, cold blood cardioplegia, and modified ultrafiltration. A bolus dose of $30 \mathrm{mg} / \mathrm{kg}$ of methylprednisolone was administered to all patients at CPB start. Inhalational anesthesia (sevoflurane or isoflurane) and intravenous fentanyl were administered to all patients. Postoperative care was delivered in the PICU by trained staff according to standard protocols. ${ }^{7}$ The teams responsible for intraoperative and postoperative care were blind to the group to which the patient belonged.
Blood samples (2.5 mL into EDTA vacuum tubes) were obtained from arterial or central venous lines, inserted before surgery, at 4, 12, 24, and 48 hours after $\mathrm{CPB}$ end for evaluation of the inflammatory response and biomarkers of myocardial dysfunction. Inflammatory response was assessed by nuclear factor kappa $\mathrm{B}(\mathrm{NF}-\kappa \mathrm{B})$ activation in leukocytes and interleukin (IL)-8 and IL-10 plasma concentrations. Because there is evidence showing an inverse correlation between natriuretic peptide type B levels and left ventricular ejection fraction in various clinical scenarios, including congenital heart disease, ${ }^{8}$ and an association between increased plasma levels of natriuretic peptide type $\mathrm{B}$ and its inactive form $\mathrm{N}$-terminal pro-B-type natriuretic peptide (NT-proBNP), as well as cardiac troponin I (cTnI) with low cardiac output syndrome in children undergoing $\mathrm{CPB},{ }^{9-12}$ NT-proBNP and cTnI were chosen as the biomarkers of myocardial dysfunction for this study.

Samples were immediately centrifuged at $10^{\circ} \mathrm{C}, 3000 \mathrm{rpm}$, and plasma was separated and stored at $-70^{\circ} \mathrm{C}$ until analysis. The pellet containing blood cells was lysed with ammonium bicarbonate plus ammonium chloride solution and centrifuged at $3000 \mathrm{rpm}$ for 15 minutes at $4^{\circ} \mathrm{C}$. The supernatant was discarded, and the remaining pellet containing RNA, DNA, and protein was resuspended in phosphate-buffered solution and Trizol LS (Invitrogen Corporation, Carlsbad, Calif), and stored at $-70^{\circ} \mathrm{C}$.

RNA was extracted using the chloroform/isopropanol/ethanol method and quantified by spectrophotometry at $260 \mathrm{~nm}$ (Eppendorf BioPhotometer Plus, Eppendorf AG, Hamburg, Germany). Its quality was assessed in $1.2 \%$ agarose gel electrophoresis. Complementary DNA was synthesized with a commercially available kit (High Capacity cDNA Reverse Transcription Kit; Applied Biosystems, Foster City, Calif), according to the manufacturer's instructions. NF- $\kappa \mathrm{B}$ activity in peripheral blood mononuclear cells and neutrophils was assessed by the relative gene expression of its inhibitor, I kappa $\mathrm{B}$ alpha $(\mathrm{I} \kappa \mathrm{B} \alpha)$ by real-time quantitative polymerase chain reaction (7500 Real Time PCR System, Applied Biosystems), ${ }^{13}$ using a TaqMan probe for human I $\alpha$ B $\alpha$ (reference: Hs_00153283_m1, Reporter: FAM) (Applied Biosystems) and $\beta$-actin (Reporter: FAM) (Applied Biosystems) as endogenous control. All tests were performed in duplicate. $\mathrm{I} \kappa \mathrm{B} \alpha$ relative gene expression was calculated by the $2^{-\Delta \Delta C \mathrm{~T}}$ method, as previously described. ${ }^{14}$ The calibrator was RNA from 12 healthy children. To validate the use of relative $\mathrm{I} \kappa \mathrm{B} \alpha$ gene expression as an indicator of NF- $\kappa \mathrm{B}$ activation, we performed the relative quantification of total NF- $\kappa$ B in the pool of proteins extracted from lysates of peripheral blood mononuclear cells by Western blot, using $\beta$-actin as endogenous control.

IL- 8 and 10 plasma concentrations were measured by enzyme-linked immunosorbent assay (BD OptEIA, BD Biosciences Pharmingen, San Diego, Calif). Plasma concentrations of cTnI were quantified by solidphase chemiluminescence immunoassay using the Immulite 1000 analyzer (Siemens Medical Solutions Diagnostics, Los Angeles, Calif). NT-proBNP plasma concentrations were measured by enzyme electrochemiluminescence immunoassay using the Cobas E 411 analyzer (Roche Diagnostics, Basel, Switzerland)

Demographic and clinical data were collected from patients' health records. An adapted inotropic score was calculated as follows: doses of dopamine + dobutamine + milrinone $\times 10+$ epinephrine $\times 100+$ norepinephrine $\times 100 .{ }^{15}$ Organ dysfunction was assessed by Pediatric Logistic Organ Dysfunction (PELOD) score. ${ }^{16}$ Procedure complexity was stratified according to RACHS- 1 score, ${ }^{5}$ and severity of illness was assessed by Pediatric Risk of Mortality score between 8 and 24 hours after PICU admission. ${ }^{17}$

The primary outcome measure was the concentration of IL- 84 hours after surgery. Secondary end points included NF- $\kappa \mathrm{B}$ activation in leukocytes; postoperative concentrations of IL-10, NT-proBNP, and cTnI; duration of mechanical ventilation; incidence of arrhythmia; PELOD score at 24 hours and on day 2; length of PICU and hospital stay; and mortality up to hospital discharge.

\section{Statistical Analysis}

Statistical analyses of data were performed using SPSS 16.0 for Windows (SPSS Inc, Chicago, Ill). The primary end point for which our sample 
size was calculated was the concentration of IL- 84 hours after surgery, because it was a good predictor of postoperative low cardiac output syndrome and a good marker of inflammation in a previous study of our group. ${ }^{12}$ In this study, we found that the difference between the means of IL- 8 concentrations 4 hours after surgery among patients who developed low cardiac output syndrome postoperatively and those who did not develop low cardiac output syndrome was $190 \mathrm{pg} / \mathrm{mL}$ (standard deviation, 155). To normalize data, logarithmic transformation was performed, and we found that the difference between means of IL- 8 concentrations 4 hours after surgery was 0.8 (standard deviation, 0.6 ). Thus, with a power of $80 \%$ and type 1 error $(\alpha)$ of $5 \%$, and experimental to control ratio of $1: 1$, we calculated a sample size of 20 subjects. The analysis was per protocol. Data were expressed as median (range) or $\mathrm{n}(\%)$. Comparisons between groups were made using the Mann-Whitney $U$ test for continuous variables and Fisher exact test for categoric variables. Variables with repeated measurements were analyzed using a linear mixed-effects model where time was included as a random factor and group membership as a fixed factor. Residuals were tested for normal distribution, with mean of 0 and variance of $\sigma^{2}$.

\section{RESULTS}

From February 2008 to February 2009, 27 children admitted to the Pediatric Cardiology ward of Hospital das Clínicas of Faculty of Medicine of Ribeirão Preto of University of São Paulo in the preoperative period were assessed for eligibility, of whom 23 were randomized. Four patients were excluded for the following reasons: age more than 2 years (2) and no consent by parents (2). Study participants were randomly assigned to the RIPC group $(\mathrm{n}=12)$ and the control group $(\mathrm{n}=11)$. One patient allocated to the control group was excluded because of intraoperative death; 22 patients were analyzed (12 in the RIPC group and 10 in the control group). The flow diagram of the study is given in Figure E1.

Patients' age ranged from 1.4 to 21.1 months (median, 5.9 months); $59 \%$ were male. RACHS- 1 category frequencies in the study population were as follows: category II, $50 \%$; category III, $31.8 \%$; category IV, $18.2 \%$ (Table 1 ).

Baseline demographic and clinical characteristics were similar in both groups, which shows that the groups were homogeneous and patients were adequately randomized (Table 2).

In the experimental group, RIPC was performed 19.1 to 27.5 hours (median, 22.1 hours) before CPB start. In all cases, the child's parent or legal guardian was present during the procedure, and in the majority of cases, RIPC was applied with the child on the caregiver's lap. Most children tolerated the procedure well, provided they were distracted. Only 2 children needed sedation with chloral hydrate 40 $\mathrm{mg} / \mathrm{kg}$, and 1 of them received also an intravenous bolus of midazolam $0.1 \mathrm{mg} / \mathrm{kg}$; they were monitored and had no complications related to sedation. No lower limb complications that could be attributed to the technique, such as swelling, petechiae, ecchymosis, or thrombosis, were observed before or after surgery.

Hemodynamic variables (heart rate, systolic blood pressure, and central venous pressure) were similar in both groups at all time points. Heart rate was significantly higher in the experimental group 48 hours after CPB end $(P=.007)$, but systolic blood pressure and central venous pressure did not change significantly over time in either group. There was no difference in the inotropic score between groups at any time point, but it decreased significantly from 24 hours after cessation of CPB in the control group $(P=.0003)$. Lactate plasma levels were similar in both groups at all times, and they showed a significant decrease equally in both groups from 12 hours after CPB end $(P<.0001)$. There was no difference between groups in urine output and creatinine concentrations, and values did not change significantly over time in either group.

There was no significant difference in cTnI concentrations between groups at any sampling time, and they decreased significantly over time similarly in both groups $(P<.0001)$ (Figure 1). NT-proBNP levels peaked in both groups 12 hours after CPB end. The RIPC group, compared with the control group, had lower NT-proBNP peak concentrations (median 8219; range 3684-23,700 vs median 20,697 ; range $7379-35,000 \mathrm{pg} / \mathrm{mL}$, respectively; $P=.02$ ), lower NT-proBNP concentrations 12 hours $(P=.03)$ and 24 hours $(P=.03)$ after cessation of CPB, and lower area under the NT-proBNP curve $(P=.02)$ (Figure 2).

The distribution of IL-8 and 10 concentrations was similar in both groups. They peaked 4 hours after CPB end in the 2 groups and subsequently decreased equally in both groups $(P<.0001$ and $P=.001$ for IL-8 in experimental and control groups, respectively; $P<.0001$ and $P=.0003$ for IL-10, in experimental and control groups, respectively) (Figure 3). The quantification of $\mathrm{I} \kappa \mathrm{B} \alpha$ gene expression also did not differ between groups at any time point, and values did not change significantly over time in either group $(P=.58$ and $P=.32$, in experimental and control groups, respectively) (Figure E2). Relative quantification of total NF- $\kappa \mathrm{B}$ in the pool of proteins extracted from lysates of peripheral blood mononuclear cells by Western blot using $\beta$-actin as endogenous control was performed in 3 randomly selected patients. We found that the relative quantification of $\mathrm{I} \kappa \mathrm{B} \alpha$ mRNA was inversely related (mirror image) to the relative quantification of total $\mathrm{NF}-\kappa \mathrm{B}$ protein (Figure E3).

No significant difference was observed regarding the duration of mechanical ventilation (median, 1 ; range, $1-8$ vs median, 1 ; range, $1-5$ days; $P=.66$ ), incidence of arrhythmia ( $4 / 12$ vs $3 / 10 ; P=1$ ), PELOD score at 24 hours (median 11 ; range $1-20$ vs median 12 ; range $1-22 ; P=.16$ ), PELOD score on day 2 (median, 0 ; range, $0-10$ vs median, 0 ; range, $0-1 ; P=.3$ ), length of PICU stay (median, 4; range, $2-27$ vs median, 5; range, $2-22$ days; $P=.76$ ), and length of hospital stay (median, 11; range, 4-43 vs median, 9.5; range, 6-28 days; $P=.86$ ) between the RIPC and control groups, respectively. There were no postoperative deaths up to hospital discharge in either group. 
TABLE 1. Demographic and clinical characteristics of all patients

\begin{tabular}{|c|c|c|c|c|}
\hline Patient & Sex & Age (mo) & Group & Diagnosis \\
\hline 1 & M & 1.4 & RIPC & Taussig-Bing anomaly \\
\hline 2 & $\mathrm{~F}$ & 1.8 & RIPC & VSD and PDA \\
\hline 3 & M & 15.8 & RIPC & Tricuspid atresia and pulmonary stenosis \\
\hline 4 & M & 13.7 & RIPC & Tetralogy of Fallot \\
\hline 5 & M & 14.3 & RIPC & Tetralogy of Fallot \\
\hline 6 & M & 21.1 & RIPC & Tetralogy of Fallot \\
\hline 7 & $\mathrm{~F}$ & 5.0 & RIPC & Hypoplastic aortic arch, coarctation of the aorta, VSD, and DORV \\
\hline 8 & M & 1.4 & RIPC & Total anomalous pulmonary venous connection (supracardiac) \\
\hline 9 & $\mathrm{~F}$ & 6.7 & RIPC & Partial atrioventricular septal defect and pulmonary stenosis \\
\hline 10 & $\mathrm{~F}$ & 4.0 & RIPC & VSD and PDA \\
\hline 11 & $\mathrm{~F}$ & 7.9 & RIPC & Partial atrioventricular septal defect and pulmonary stenosis \\
\hline 12 & M & 3.0 & RIPC & VSD and PDA \\
\hline 13 & $\mathrm{~F}$ & 13.9 & Control & Total atrioventricular septal defect \\
\hline 14 & $\mathrm{~F}$ & 1.4 & Control & Hypoplastic aortic arch and coarctation of the aorta \\
\hline 15 & $\mathrm{~F}$ & 3.3 & Control & Hypoplastic aortic arch, coarctation of the aorta, and VSD \\
\hline 16 & M & 12.4 & Control & Tetralogy of Fallot \\
\hline 17 & M & 1.4 & Control & d-Transposition of the great arteries and VSD \\
\hline 18 & M & 5.1 & Control & VSD and PDA \\
\hline 19 & M & 2.1 & Control & 1-Transposition of the great arteries and DORV \\
\hline 20 & $\mathrm{~F}$ & 10.3 & Control & Mitral atresia and DORV \\
\hline 21 & M & 8.9 & Control & Tetralogy of Fallot \\
\hline 22 & M & 7.2 & Control & VSD and pulmonary stenosis \\
\hline
\end{tabular}

$V S D$, Ventricular septal defect; $P A$, pulmonary artery; $P D A$, patent ductus arteriosus; $D O R V$, double-outlet right ventricle.

\section{DISCUSSION}

This is the first clinical study in children that assessed the effect of RIPC performed only on the day before cardiac surgery. Our data showed that children aged less than 2 years with complex congenital heart disease undergoing RIPC approximately 24 hours before surgery had lower postoperative levels of NT-proBNP compared with a control group. Nevertheless, clinical parameters of low cardiac output syndrome and the inotropic score, as well as the systemic inflammatory response, were similar in both groups. In addition, no significant differences were found in clinical outcomes between the experimental and the control group.

It has been shown that children with various congenital heart defects undergoing RIPC in the operating room immediately before surgery had lower postoperative levels of troponin I (TnI), less inotropic requirement, and a more favorable cytokine profile. ${ }^{18}$ In addition, children undergoing surgical repair of ventricular septal defects who received RIPC 24 hours and 1 hour before surgery start had reduced $\mathrm{TnI}$ release, decreased inotropic need, lower levels of proinflammatory cytokines, and higher levels of IL-10 in the postoperative period. ${ }^{19}$

Studies in adults undergoing elective coronary artery bypass graft surgery showed lower troponin $T$ release in those receiving the RIPC stimulus immediately before surgery. ${ }^{20,21}$ In addition, a recently published study that evaluated RIPC performed only on the day before heart surgery showed that adults submitted to coronary artery

TABLE 2. Comparisons of demographic and clinical characteristics between groups

\begin{tabular}{lccc}
\hline \multicolumn{1}{c}{ Characteristics } & RIPC group $(\mathbf{n}=\mathbf{1 2})$ & Control group $(\mathbf{n}=\mathbf{1 0})$ & $\boldsymbol{P}$ value \\
\hline Gender (male) & $7(58 \%)$ & $6(60 \%)$ & 1.00 \\
Age at surgery (mo) & $5.8(1.4-21.1)$ & $6.1(1.4-13.9)$ & .64 \\
Weight $(\mathrm{kg})$ & $5.3(2.7-11.4)$ & $4.9(3.0-7.0)$ & .59 \\
Length $(\mathrm{cm})$ & $60.5(49-85)$ & $61.5(52-74)$ & .64 \\
Body surface area $\left(\mathrm{m}^{2}\right)$ & $0.3(0.2-0.5)$ & $0.3(0.2-0.4)$ & .59 \\
Preoperative $\mathrm{O}_{2}$ saturation $(\%)$ & $94(58-97)$ & $92(78-97)$ & .84 \\
Surgery time (min) & $187(140-300)$ & $195(150-310)$ & .91 \\
Bypass time (min) & $92(55-175)$ & $90(35-175)$ & .97 \\
Aortic crossclamp time (min) & $66(5-120)$ & $59(0-113)$ & .42 \\
PRISM score & $6.5(1-15)$ & $10.5(0-19)$ & .11 \\
RACHS-1 score (III/ IV) & $5(42 \%)$ & $6(60 \%)$ & .26 \\
\hline
\end{tabular}

Data are expressed as median (range) or $\mathrm{n}(\%)$. RPIC, Remote ischemic preconditioning; PRISM, Pediatric Risk of Mortality; RACHS, Risk Adjustment for Congenital Heart Surgery. 


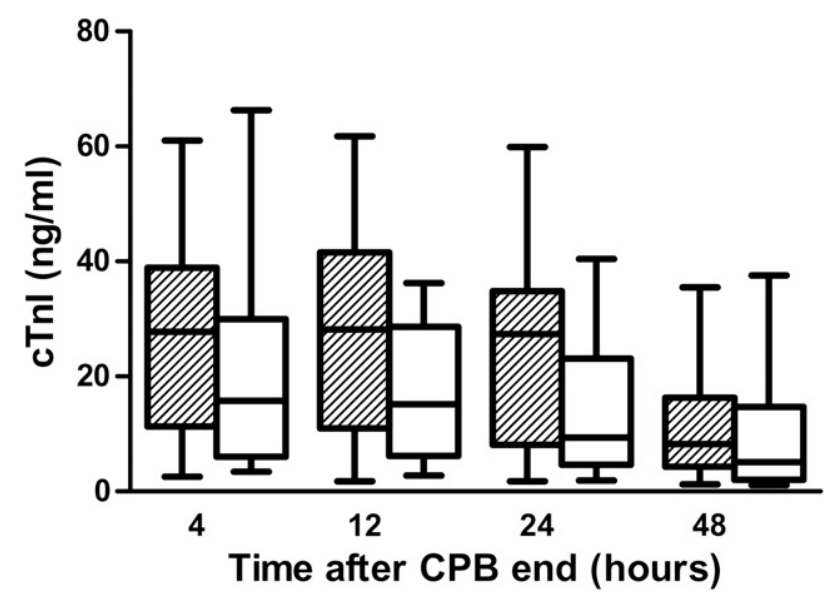

FIGURE 1. Postoperative cTnI plasma levels in patients from RIPC (hashed boxes) and control (white boxes) groups. Central lines are medians, boxes are interquartile ranges, and brackets are total range. $C P B$, Cardiopulmonary bypass; $c T n I$, cardiac troponin I.

bypass grafting who received RIPC 18 hours before surgery start had lower levels of TnI 8 hours postoperatively. ${ }^{22}$ However, morbidity and mortality were not reported in any of these studies.

In the present study, we observed that levels of cTnI were not significantly different between groups. On the other hand, NT-proBNP release was significantly reduced in children receiving the preconditioning stimulus, which could indicate less myocardial dysfunction and a cardioprotective effect elicited by late RIPC. Nonetheless, the significant reduction in the biochemical parameter of myocardial dysfunction did not translate into morbidity improvement. In addition, there was no postoperative mortality in either group, which is not surprising because death is a rare event in pediatric cardiac surgery. Moreover, we only studied children who were stable in the preoperative period; neonates and those admitted preoperatively to the PICU, who have a greater risk of mortality, were not included in this study.

Contrary to our expectations, we did not observe any beneficial effect in the inflammatory response that could be attributed to RIPC. Our findings are in contrast with previously published data showing suppression of proinflammatory gene transcription in human leukocytes after RIPC. ${ }^{5}$ In our study, there was no difference in plasma concentrations of the proinflammatory cytokine IL-8 and the antiinflammatory cytokine IL-10 between the RIPC and control groups. I $\kappa \mathrm{B} \alpha$ gene expression, which has been shown to correlate well with NF- $\kappa$ B activation, ${ }^{13}$ was also similar in both groups. The inverse association between the relative quantification of $\mathrm{I} \kappa \mathrm{B} \alpha$ mRNA and the relative quantification of total NF- $\kappa$ B protein observed in this study is consistent with the fact that when NF- $\kappa$ B binds to DNA, and thus its relative quantification decreases in the pool of proteins, the relative amount of $\mathrm{I} \kappa \mathrm{B} \alpha$ mRNA increases because of its transcription induced by NF- $\kappa \mathrm{B}$ binding to DNA.

Ischemic preconditioning may fail to protect the heart when the subsequent ischemic insult is too long. ${ }^{23}$ Therefore, the long duration of ischemia induced by cardiac surgery may overwhelm the protective effect of RIPC. However, in our study, CPB and crossclamp times were not excessively long ( $\sim 90$ and 60 minutes, respectively, in both groups). The question arises whether additional cardioprotection could be observed if early and late RIPC were applied in combination, as already demonstrated. ${ }^{19}$ In addition, the beneficial effect of longer occlusion periods during preconditioning needs to be explored in further studies.

In the present study, we verified that the protocol of RIPC using cuff pressures $15 \mathrm{~mm} \mathrm{Hg}$ above systolic blood pressure was harmless to the children's limbs. We also added the information that it is possible to apply the technique in young infants, without any sedation in most cases.

\section{Limitations}

This study has some limitations. First, blood samples for assessment of baseline biochemical markers of myocardial dysfunction and inflammatory response were not collected because we assumed that they would be in the normal range for age, because all patients were stable in the preoperative period. Second, steroid administration at CPB start and
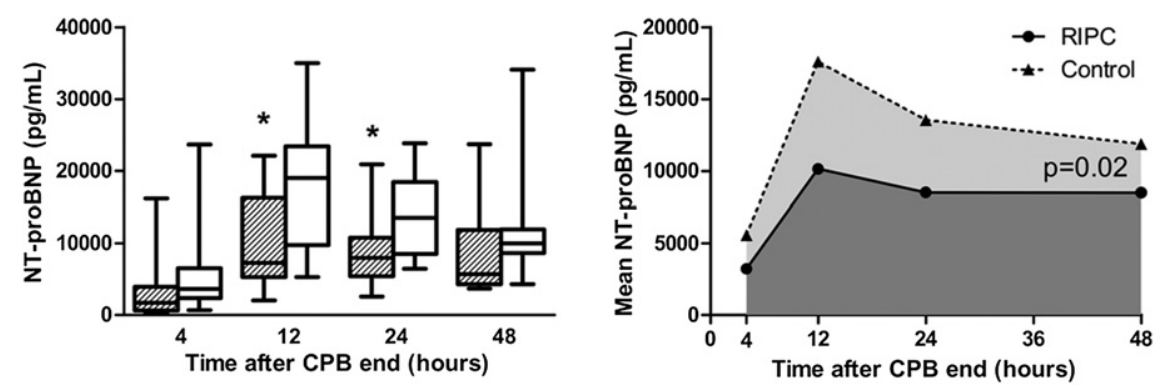

FIGURE 2. Left: Postoperative NT-proBNP plasma levels in patients from RIPC (hashed boxes) and control (white boxes) groups. Central lines are medians, boxes are interquartile ranges, and brackets are total range. Right: Areas under the curve of postoperative plasma NT-proBNP mean values in patients from RIPC (dark gray) and control (light gray) groups. $* P=.03$. CPB, Cardiopulmonary bypass; NT-proBNP, N-terminal pro-B-type natriuretic peptide; $R I P C$, remote ischemic preconditioning. 

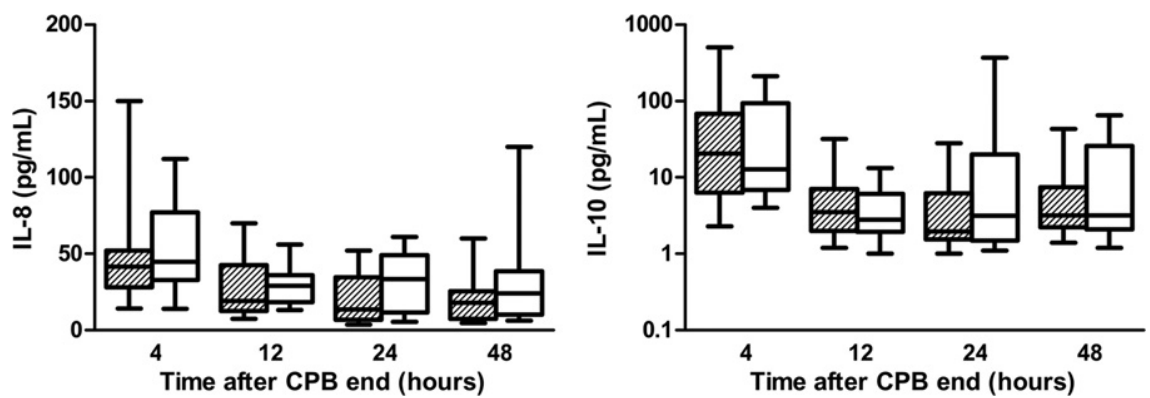

FIGURE 3. Postoperative IL-8 (left) and IL-10 (right) plasma levels in patients from RIPC (hashed boxes) and control (white boxes) groups. Central lines are medians, boxes are interquartile ranges, and brackets are total range. $C P B$, Cardiopulmonary bypass; $I L$, interleukin.

modified ultrafiltration could have attenuated the postoperative inflammatory response, overpowering any effect elicited by RIPC. Finally, the number of patients included in the study had no power to assess mortality.

\section{CONCLUSIONS}

Children undergoing RIPC on the day before cardiac surgery had lower levels of NT-proBNP postoperatively, which could indicate less myocardial dysfunction after CPB. Nevertheless, this finding lacked clinical significance. Thus, routine application of late RIPC alone for cardioprotection in children with congenital heart disease undergoing cardiac surgery with CPB currently cannot be recommended. Future studies are needed to establish the "dose of ischemia" and the best moment to perform the procedure.

The authors thank Vanessa S. Silveira, PhD, who performed the Western blot analyses, and Leticia F. Leal, MSc, for the contribution with real-time quantitative polymerase chain reaction techniques.

\section{References}

1. Hausenloy DJ, Yellon DM. Remote ischaemic preconditioning: underlying mechanisms and clinical application. Cardiovasc Res. 2008;79:377-86.

2. Hausenloy DJ, Yellon DM. The second window of preconditioning (SWOP) where are we now? Cardiovasc Drugs Ther. 2010;24:235-54

3. Kharbanda RK, Nielsen TT, Redington AN. Translation of remote ischaemic into clinical practice. Lancet. 2009;374:1557-65.

4. Wang L, Oka N, Tropak M, Callahan J, Lee J, Wilson G, et al. Remote ischemic preconditioning elaborates a transferable blood-borne effector that protects mitochondrial structure and function and preserves myocardial performance after neonatal cardioplegic arrest. J Thorac Cardiovasc Surg. 2008;136:335-42.

5. Konstantinov IE, Arab S, Kharbanda RK, Li J, Cheung MM, Cherepanov V, et al. The remote ischemic preconditioning stimulus modifies inflammatory gene expression in humans. Physiol Genomics. 2004;19:143-50.

6. Jenkins KJ. Risk adjustment for congenital heart surgery: the RACHS-1 method. Semin Thorac Cardiovasc Surg Pediatr Card Surg Annu. 2004;7:180-4.

7. Roth SJ. Postoperative care. In: Chang AC, Hanley FL, Wernovsky G, Wessel DL, eds. Pediatric Cardiac Intensive Care. Baltimore: Lippincott Williams \& Wilkins; 1998;163-87.

8. Breuer T, Sápi E, Skoumal R, Tóth M, Ala-Kopsala M, Vuolteenaho O, et al. $\mathrm{N}$-terminal probrain natriuretic peptide level inversely correlates with cardiac index after arterial switch operation in neonates. Paediatr Anaesth. 2007;17:782-8.
9. Hsu JH, Keller RL, Chikovani O, Cheng H, Hollander SA, Karl TR, et al. B-type natriuretic peptide levels predict outcome after neonatal cardiac surgery. $J$ Thorac Cardiovasc Surg. 2007;134:939-45.

10. Shih CY, Sapru A, Oishi P, Azakie A, Karl TR, Harmon C, et al. Alterations in plasma B-type natriuretic peptide levels after repair of congenital heart defects: a potential perioperative marker. J Thorac Cardiovasc Surg. 2006;131: 632-8.

11. Froese NR, Sett SS, Mock T, Krahn GE. Does troponin-I measurement predict low cardiac output syndrome following cardiac surgery in children? Crit Care Resusc. 2009;11:116-21.

12. Carmona F, Manso PH, Vicente WVA, Castro M, Carlotti AP. Risk stratification in neonates and infants submitted to cardiac surgery with cardiopulmonary bypass: a multimarker approach combining inflammatory mediators, N-termina pro-B-type natriuretic and troponin I. Cytokine. 2008;42:317-24.

13. Bottero V, Imbert V, Frelin C, Formento JL, Peyron JF. Monitoring NF-kappa B transactivation potential via real-time PCR quantification of I kappa B-alpha gene expression. Mol Diagn. 2003;7:187-94.

14. Livak KJ, Schmittgen TD. Analysis of relative gene expression data using realtime quantitative PCR and the 2(-Delta Delta C(T)) Method. Methods. 2001; 25:402-8.

15. Wernovsky G, Wypij D, Jonas RA, Mayer JE Jr, Hanley FL, Hickey PR, et al Postoperative course and hemodynamic profile after the arterial switch operation in neonates and infants. A comparison of low-flow cardiopulmonary bypass and circulatory arrest. Circulation. 1995;92:2226-35.

16. Leteurtre S, Martinot A, Duhamel A, Proulx F, Grandbastien B, Cotting J, et al. Validation of the paediatric logistic organ dysfunction (PELOD) score: prospective, observational, multicentre study. Lancet. 2003;362:192-7.

17. Pollack MM, Ruttimann UE, Getson PR. Pediatric risk of mortality (PRISM) score. Crit Care Med. 1988;16:1110-6.

18. Cheung MMH, Kharbanda RK, Konstantinov IE, Shimizu M, Frndova H, Li J, et al. Randomized controlled trial of the effects of remote ischemic preconditioning on children undergoing cardiac surgery. First clinical application in humans. $J$ Am Coll Cardiol. 2006;47:2277-82.

19. Zhou W, Zeng D, Chen R, Liu J, Yang G, Liu P, et al. Limb ischemic preconditioning reduces heart and lung injury after an open heart operation in infants. $P e-$ diatr Cardiol. 2010;31:22-9.

20. Hausenloy DJ, Mwamure PK, Venugopal V, Harris J, Barnard M, Grundy E, et al Effect of remote ischaemic preconditioning on myocardial injury in patients undergoing coronary artery bypass graft surgery: a randomised controlled trial Lancet. 2007:370:575-9.

21. Venugopal V, Hausenloy DJ, Ludman A, Di Salvo C, Kolvekar S, Yap J, et al. Remote ischaemic preconditioning reduces myocardial injury in patients undergoing cardiac surgery with cold-blood cardioplegia: a randomised controlled trial. Heart. 2009;95:1567-71

22. Wagner R, Piler P, Bedanova H, Adamek P, Grodecka L, Freiberger T. Myocardial injury is decreased by late remote ischaemic preconditioning and aggravated by tramadol in patients undergoing cardiac surgery: a randomised controlled trial. Interact Cardiovasc Thorac Surg. 2010;11:758-62.

23. Murry CE, Jennings RB, Reimer KA. Preconditioning with ischemia: a delay of lethal cell injury in ischemic myocardium. Circulation. 1986;74:1124-36. 


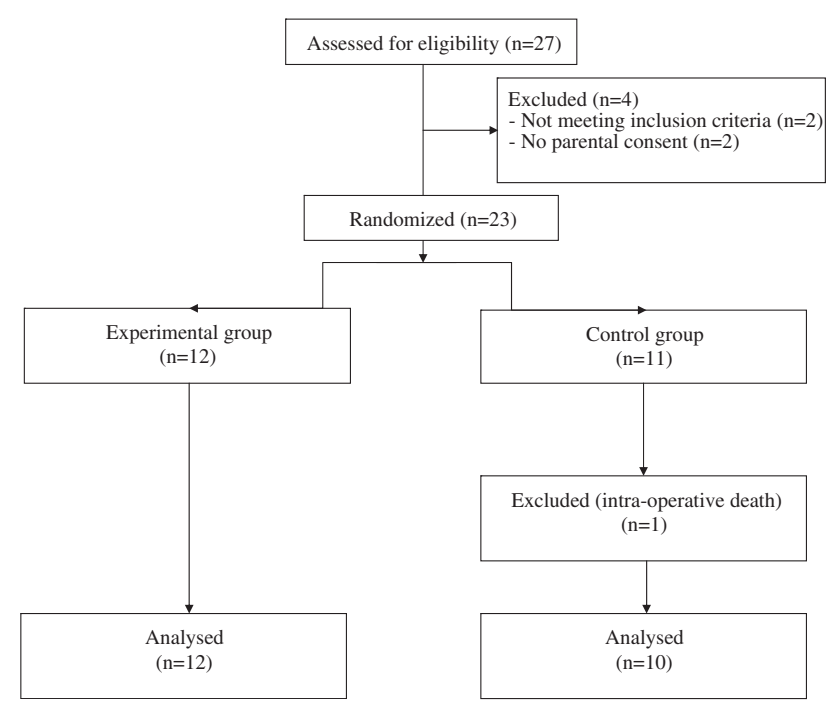

FIGURE E1. Flow diagram of the study.

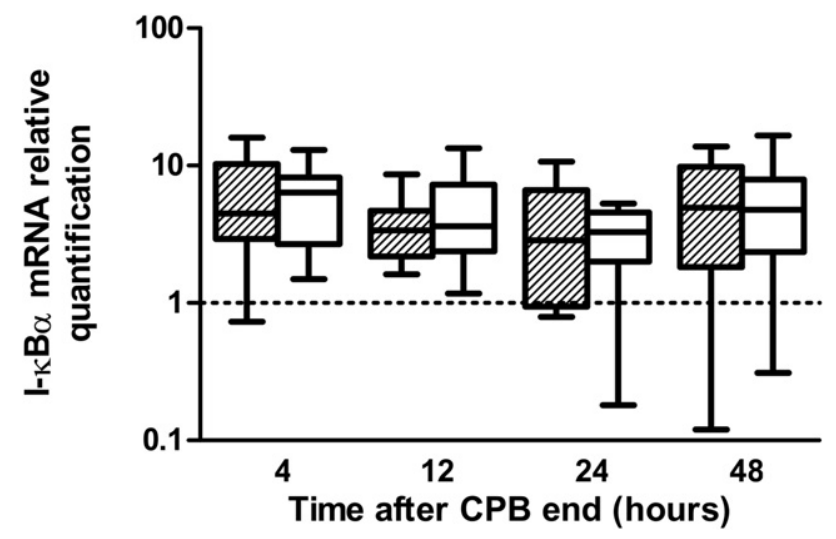

FIGURE E2. Postoperative $\mathrm{I} \kappa \mathrm{B} \alpha$ mRNA relative quantification in patients from RIPC (hashed boxes) and control (white boxes) groups. Central lines are medians, boxes are interquartile ranges, and brackets are total range. $C P B$, Cardiopulmonary bypass; $I \kappa B \alpha$, I kappa $\mathrm{B}$ alpha.
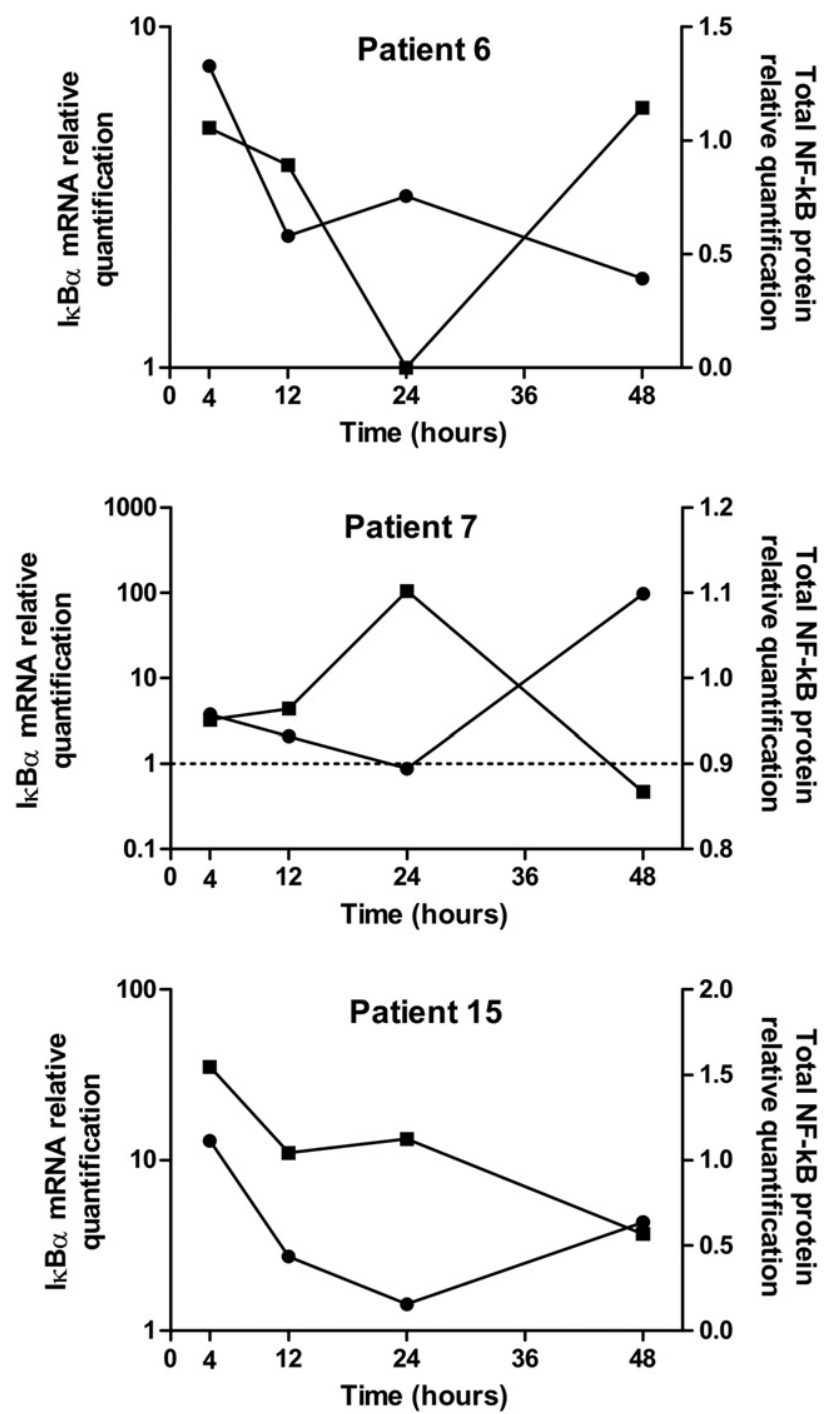

FIGURE E3. Postoperative $\mathrm{I} \kappa \mathrm{B} \alpha$ mRNA relative quantification and total $\mathrm{NF}-\kappa \mathrm{B}$ protein relative quantification of 3 randomly selected patients. $I \kappa B \alpha$, I kappa $\mathrm{B}$ alpha; $N F-\kappa B$, nuclear factor kappa $\mathrm{B}$. 